\title{
Clinical evaluation and animal experimental study of different mass concentrations of pingyangmycin in the local injection treatment of lip venous malformation
}

\author{
Weili Yuan $^{1 \wedge}$, Xukai Wang ${ }^{2}$, Lei Xue ${ }^{2}$, Fang Zhang ${ }^{3}$ \\ ${ }^{1}$ Department of Stomatology, The Fourth Affiliated Hospital of China Medical University, Shenyang, Liaoning, China; ${ }^{2}$ Department of Oral and \\ Maxillofacial Surgery, School of Stomatology, China Medical University, Liaoning Institute of Stomatology, Shenyang, Liaoning, China; ${ }^{3}$ Department of \\ Otorhinolaryngology Head and Neck Surgery, The Fourth Affiliated Hospital of China Medical University, Shenyang, Liaoning, China \\ Contributions: (I) Conception and design: W Yuan, X Wang; (II) Administrative support: W Yuan, X Wang; (III) Provision of study materials or \\ patients: W Yuan, X Wang; (IV) Collection and assembly of data: W Yuan, L Xue, F Zhang; (V) Data analysis and interpretation: W Yuan; (VI) \\ Manuscript writing: All authors; (VII) Final approval of manuscript: All authors. \\ Correspondence to: Weili Yuan. Department of Stomatology, The Fourth Affiliated Hospital of China Medical University. No. 4, Chongshan \\ East Road, Shenyang 110032, China. Email: yuanweilicmu@163.com; Xukai Wang. Department of Oral and Maxillofacial Surgery, School of \\ Stomatology, China Medical University. No. 117, Nanjing North Street, Shenyang 110002, China. Email: wangxukai757892@sina.com.
}

Background: This study investigated the clinical efficacy of different mass concentrations of pingyangmycin in the local injection treatment of lip venous malformation. An animal experimental study of the histopathological effects of different mass concentrations of pingyangmycin on the normal lip tissue of rabbits was also conducted.

Methods: (I) We retrospectively analysed 98 out-patients with lip venous malformation in the Stomatological Hospital and the Fourth Affiliated Hospital of China Medical University from January 2008 to June 2013. The 98 cases were treated by local injection of different mass concentrations $(8 \mathrm{mg} / 3 \mathrm{~mL}$ and $8 \mathrm{mg} / 5 \mathrm{~mL}$ ) of pingyangmycin for the different sites of the lips. The clinical efficacy was observed, and adverse reactions were recorded. (II) 60 healthy male rabbits were randomly divided into three groups: a $8 \mathrm{mg} / 5 \mathrm{~mL}$ pingyangmycin group, a $8 \mathrm{mg} / 3 \mathrm{~mL}$ pingyangmycin group, and a control group. The right upper lips of the experimental groups were injected with $1 \mathrm{ml}$ pingyangmycin $(8 \mathrm{mg} / 5 \mathrm{~mL})$ and $1 \mathrm{ml}$ pingyangmycin $(8 \mathrm{mg} / 3 \mathrm{~mL})$ respectively, and the control group was injected with the same volume of normal saline. The thickness of the right upper lip of rabbits in the experimental groups and the control group was measured on the $21 \mathrm{st}, 28 \mathrm{th}, 35 \mathrm{th}$, and 60 th days after the first injection. Histopathological changes at the injection site were observed by light microscope and transmission electron microscope.

Results: Venous malformations involving the skin tissues of the lips (pingyangmycin $8 \mathrm{mg} / 3 \mathrm{~mL}$ ) had an effective rate of $93.62 \%$, and those involving the labial mucosa tissues (pingyangmycin $8 \mathrm{mg} / 5 \mathrm{~mL}$ ) had an effective rate of $98.04 \%$. In the animal experiment, there were statistically significant differences in the thickness of the injection site among the $8 \mathrm{mg} / 3 \mathrm{~mL}$ group, $8 \mathrm{mg} / 5 \mathrm{~mL}$ group, and the control group at different time points $(\mathrm{P}<0.01)$.

Conclusions: The local injection of pingyangmycin in the treatment of lip venous malformations was efficient, safe and reliable. In the process of clinical application, attention should be paid when the concentration is $8 \mathrm{mg} / 3 \mathrm{~mL}$ to avoid local tissue atrophy and other complications.

Keywords: Pingyangmycin; mass concentration; lips; venous malformations; sclerotherapy; histopathology

Submitted Apr 02, 2021. Accepted for publication May 10, 2021.

doi: 10.21037/atm-21-2018

View this article at: http://dx.doi.org/10.21037/atm-21-2018

^ ORCID: 0000-0001-5701-8023. 


\section{Introduction}

Vascular malformations are a group of congenital diseases characterized by vascular structural dysfunction caused by primitive vascular development disorders or abnormalities in the embryonic period. In a study by Redondo (1), the main pathological features were found to be a thin and monolayer basement membrane, vascular wall dysplasia, and a lumen lining formed by flat and static vascular endothelial cells. The incidence rate of vascular malformation is about 1:5,000 to 10,000 , and while the disease can occur in all parts of the body, about $40 \%$ occur in the head and neck $(2,3)$. Waner and Suen classified the disease according to the anatomical characteristics of diseased vessels into microvenous malformations, venous malformations, arteriovenous malformations, lymphatic vascular malformations, and mixed vascular malformations, among which venous malformations were the most common clinically $(4,5)$. Venous malformations often occur in the cheek, lip, tongue, floor of the mouth, soft palate, parapharynx, and neck. These lesions exist at birth and do not regress naturally. Expansion of the lesions can cause deformities and dysfunction of the face, lip, cheek, tongue and neck, causing great mental and psychological stress to patients and their families, and may also block the respiratory and digestive tracts and hinder pronunciation and eating, leading to infection, ulceration, bleeding, asphyxia, and even death $(5,6)$.

Pingyangmycin is an antibiotic antitumor drug isolated from actinomycin culture medium in the soil of Pingyang County, Zhejiang Province, China and is similar to bleomycin A5, which is a mature antitumor drug in clinical application (7). In recent years, several clinical reports on the treatment of venous malformations by pingyangmycin have produced satisfactory results (8-12). The most common site of venous formation is the lip, and as this is an important symbol of facial aesthetics, the treatment of venous malformation of the lip should not only achieve the purpose of cure, but also take into account these cosmetic considerations. In clinical work, our research group found that the local injection of pingyangmycin with different mass concentrations could achieve a greater clinical effect according to the different incidence sites of lip venous malformations. It is worth noting that we also observed some adverse reactions such as local tissue atrophy of the lip during the treatment. In view of this, we investigated the histopathological effects of local pingyangmycin injection with different mass concentrations on rabbit normal lip tissues to provide a valuable reference dose and concentration for clinical application.

We present the following article in accordance with the STROBE reporting checklist (available at http://dx.doi. org/10.21037/atm-21-2018).

\section{Methods}

\section{Clinical case data}

We enrolled 98 outpatients with lip venous malformation who were treated by the local injection of pingyangmycin in the Department of Oral and Maxillofacial surgery, at the Affiliated Stomatological Hospital of China Medical University and the Fourth Affiliated Hospital of China Medical University from January 2008 to June 2013. The patients were diagnosed with venous malformation according to their medical history, clinical features, and auxiliary combination of color Doppler ultrasound, enhanced CT, or MRI. There were 45 males and 53 females with an average age of 26 years (range, 6-78 years), and patients had not received prior treatment. All cases were located in the lip, including 47 involving the skin and subcutaneous tissue and 51 involving the red mucosa and submucosa. The minimum surface of the lesions was $0.5 \mathrm{~cm}$ $\times 0.8 \mathrm{~cm}$ and the maximum was $8 \mathrm{~cm} \times 10 \mathrm{~cm}$. The research plan was reviewed and approved by the medical ethics committee of the Stomatological Hospital of China Medical University and the Fourth Affiliated Hospital of China Medical University. The medication plan was approved by patients and their families, and informed consent was signed prior to treatment. All procedures performed in this study involving human participants were in accordance with the Declaration of Helsinki (as revised in 2013).

\section{Inclusion and exclusion criteria}

The inclusion criteria were as follows: (I) the patient had not received any other drug treatment before the treatment; (II) according to the patient's history and clinical characteristics, combined with color Doppler ultrasound, enhanced CT or MRI and other auxiliary examinations, the patient was diagnosed as having a lip venous malformation; (III) the results of chest anteroposterior and lateral radiographs, electrocardiogram, blood routine test, coagulation test, and liver and kidney function tests were normal; (IV) patients with complete clinical data had good compliance and were 
able to complete various examinations; $(\mathrm{V})$ patients and their families signed informed consent before treatment.

The exclusion criteria were any of the following: (I) according to the classification of vascular diseases proposed by Waner and Suen (4), hemangioma and other vascular malformations were present. (II) patients with acute inflammation or mucositis of the lip; (III) patients with platelet crisis or coagulation dysfunction; (IV) patients with severe liver and kidney dysfunction; (V) a history of drug allergy to pingyangmycin or bleomycin.

\section{Treatment methods}

\section{Pingyangmycin injection solution preparation method}

For venous malformation on the surface or subcutaneous tissue of the lip skin, pingyangmycin $8 \mathrm{mg}(8 \mathrm{mg} / \mathrm{piece}$, produced by Tianjin Taihe Pharmaceutical Co., Ltd., China, national drug approval number: H12020933), $1.5 \mathrm{~mL} \mathrm{2 \%}$ lidocaine, and $1.5 \mathrm{~mL} 0.9 \%$ normal saline were used. For venous malformation of the labial mucosa and submucosal tissue, pingyangmycin $8 \mathrm{mg}, 2.5 \mathrm{~mL} 2 \%$ lidocaine, and $2.5 \mathrm{~mL} 0.9 \%$ normal saline were used (13).

\section{Injection method}

After routine lip disinfection, a No.5 syringe was used to inject normal skin or mucosal tissue adjacent to the venous malformation. Blood return remained in the puncture, blood in the lesion cavity was drained as far as possible, and the needle head was kept in the lesion. The syringe containing pingyangmycin was then replaced and the drug solution evenly injected into the pathological cavity. According to the location of the lesion, the patient's age, and the extent and depth of involvement, between 1-5 $\mathrm{mL}$ was injected. After the injection, the local pinhole was pressed with a sterilized cotton ball for 5 minutes to prevent the injection liquid from spilling out. Small superficial venous malformations could be injected until the surface of the lesion became pale, and if the lesion involved a large area or had a huge volume, a multi-point injection or multiple regional injection was given. After injection, finger or ring pressure was used to compress the area for 15-30 minutes to block the blood flow and prolong the local residence time of pingyangmycin. In our study, small lesions were cured by only one injection, larger lesions were injected between three and five times, and the cumulative injection volume totaled less than $40 \mathrm{mg}$. The vital signs of patients were closely observed for at least 30 minutes after injection, when those without abnormal allergic symptoms and signs were allowed to leave the hospital. Postoperative anti-infection treatment lasted for 3-5 days. The injection was repeated 15-30 days later, and at each follow-up visit, the lesion volume, surface color, and texture changes were recorded in detail. Treatment continued or discontinued according to the degree of disease regression or adverse reactions, respectively. Digital photos were collected for archiving at each visit.

\section{Efficacy evaluation criteria}

Clinical efficacy after injection was divided into four grades. (I) Cured: the lesion completely disappeared, the surface color returned to normal and there was no recurrence at followup; (II) Basically cured: the lesions largely disappeared, the volume was reduced by more than $80 \%$, the skin color was close to normal or only slightly pigmented, and there was no dysfunction. However, the appearance was not completely restored to normal and further treatment was needed; (III) Improvement: the volume of the lesion was significantly reduced but had not reached $2 / 3$ of the lesion volume, and more treatment was required; (IV) Ineffective: the lesion volume did not shrink, remained unchanged, or continued to increase in size (14).

\section{Experimental methods}

\section{Experimental animals}

We selected 60 healthy male rabbits, all of which were pure-bred big-ear white rabbits from Japan and weighing $3.5 \mathrm{~kg}$. The laboratory animal department of China Medical University provided experimental animals and fed them in separate cages.

\section{Injection drug and preparation method}

(I) $8 \mathrm{mg} / 5 \mathrm{~mL}$ pingyangmycin injection: $8 \mathrm{mg}$ pingyangmycin $(8 \mathrm{mg} /$ piece, produced by the Tianjin Taihe Pharmaceutical Co. Ltd., national drug approval number: $\mathrm{H} 12020933$ ) was dissolved in $2.5 \mathrm{~mL} 2 \%$ lidocaine and $2.5 \mathrm{~mL} 0.9 \%$ normal saline; (II) $8 \mathrm{mg} / 3 \mathrm{~mL}$ pingyangmycin injection: $8 \mathrm{mg}$ pingyangmycin was dissolved in $1.5 \mathrm{~mL}$ of $2 \%$ lidocaine and $1.5 \mathrm{~mL}$ of $0.9 \%$ normal saline.

\section{Grouping of experimental animals}

The 60 rabbits were randomly divided into a pingyangmycin $8 \mathrm{mg} / 5 \mathrm{~mL}$ group, pingyangmycin $8 \mathrm{mg} / 3 \mathrm{~mL}$ group, and normal saline control group, with 20 rabbits in each. Each 
Table 1 Analysis of the therapeutic effects of different mass concentrations of pingyangmycin injection in the treatment of lip venous malformation

\begin{tabular}{|c|c|c|c|c|c|c|c|c|c|}
\hline Group & $\mathrm{n}$ & \multicolumn{2}{|c|}{ Cured } & \multicolumn{2}{|c|}{ Basically cured } & \multicolumn{2}{|c|}{ Improvement } & \multicolumn{2}{|c|}{ Ineffective } \\
\hline $8 \mathrm{mg} / 3 \mathrm{~mL}$ & 47 & 21 & 44.68 & 18 & 38.30 & 5 & 10.64 & 3 & 6.38 \\
\hline $8 \mathrm{mg} / 5 \mathrm{~mL}$ & 51 & 30 & 58.82 & 17 & 33.33 & 3 & 5.88 & 1 & 1.96 \\
\hline Total & 98 & 51 & 52.04 & 35 & 35.71 & 8 & 8.16 & 4 & 4.08 \\
\hline
\end{tabular}

group was further divided into four subgroups with five rabbits in each subgroup.

\section{Injection method}

After the rabbits were anesthetized and the injection sites were disinfected, the right upper lips were punctured with a No.5 injection needle, which was as deep as the muscle layer. No blood was drawn from the injection site, and the rabbits were slowly injected with a $1 \mathrm{ml}$ injection of $8 \mathrm{mg} / 5 \mathrm{~mL}$ or $8 \mathrm{mg} / 3 \mathrm{~mL}$ pingyangmycin. After the needle was withdrawn, the needle hole was immediately pressed with a sterilized cotton ball to prevent the injection liquid from spilling out. After pressing for 5 minutes, the injection pinhole was marked with a marker for the second injection. The rabbits in the control group were injected with $1 \mathrm{ml}$ normal saline on the right upper lip by the same method. Two weeks after the first injection, each experimental group and control group were injected with the same dose and concentration at the same site. After injection, the animals were reared in separate cages.

\section{Measurement of the lip thickness of rabbits and experimental tissue sampling}

Before injection, the thickness of the injection site on the right upper lip of rabbits in the control group and the experimental groups was measured. On the 21st, 28th, 35 th, and 60th day after injection, the lip thickness was again measured at the injection site point (i.e., each injection time point corresponded to a subgroup in the experimental group and the control group). Each injection site point was measured three times and the average value was taken. Tissues of each rabbit were cut from the local injection site and divided into two pieces, with one specimen fixed with $10 \%$ formaldehyde and sectioned with HE staining for observation by light microscope, and the other fixed by glutaraldehyde and prepared by transmission electron microscopy.

\section{Statistical analysis}

All data were statistically analyzed by SPSS 22.0 software, and the measurement data were expressed as mean \pm standard deviation (SD). One-way ANOVA was used for comparison among multiple groups, while independent sample $t$ test was used for comparison between the two groups. $\mathrm{P}<0.05$ indicated that the difference was statistically significant.

\section{Results}

\section{Clinical efficacy analysis}

The 98 patients were treated with a local injection of pingyangmycin of different concentrations in the treatment of lip venous malformation, and the curative effect is analyzed in Table 1. Among them, 51 cases were cured, and the overall cure rate was $52.04 \%$. The overall effective rate (cured + basically cured + improvement) was $95.92 \%$ and the effective rate of venous malformations involving the lip skin and subcutaneous tissue (pingyangmycin injection mass concentration $8 \mathrm{mg} / 3 \mathrm{~mL}$ ) was $93.62 \%$. The effective rate (cured + basically cured + improvement) of venous malformations involving the red mucosa and submucosal tissues of the lips (pingyangmycin injection mass concentration $8 \mathrm{mg} / 5 \mathrm{~mL}$ ) was $98.04 \%$. Venous malformation of the red lip mucosa with lesser volume could be cured by one injection, while three to five injections were often needed for a large volume of those of the skin and subcutaneous tissue of the lip. Adverse reactions during the treatment are shown in Table 2, and Figures 1-5 shows the comparison of efficacy of typical cases.

\section{Changes of lip tissue thickness in experimental and control groups}

The thickness of the injection site on the right upper 
Table 2 Comparison of adverse reactions of different mass concentrations of pingyangmycin injection in the treatment of lip venous malformation

\begin{tabular}{lcccccccc}
\hline \multirow{2}{*}{ Group } & \multicolumn{7}{c}{ Adverse reactions } & \\
\cline { 2 - 9 } & Tissue atrophy & Fever & Ulcer & Pulmonary fibrosis & Loss of appetite & Allergic reaction & Skin itch & Leukopenia \\
\hline $8 \mathrm{mg} / 3 \mathrm{~mL}$ & 3 & 6 & 2 & 0 & 3 & 0 & 3 & 0 \\
$8 \mathrm{mg} / 5 \mathrm{~mL}$ & 0 & 5 & 1 & 0 & 2 & 0 & 0 & 0 \\
\hline
\end{tabular}
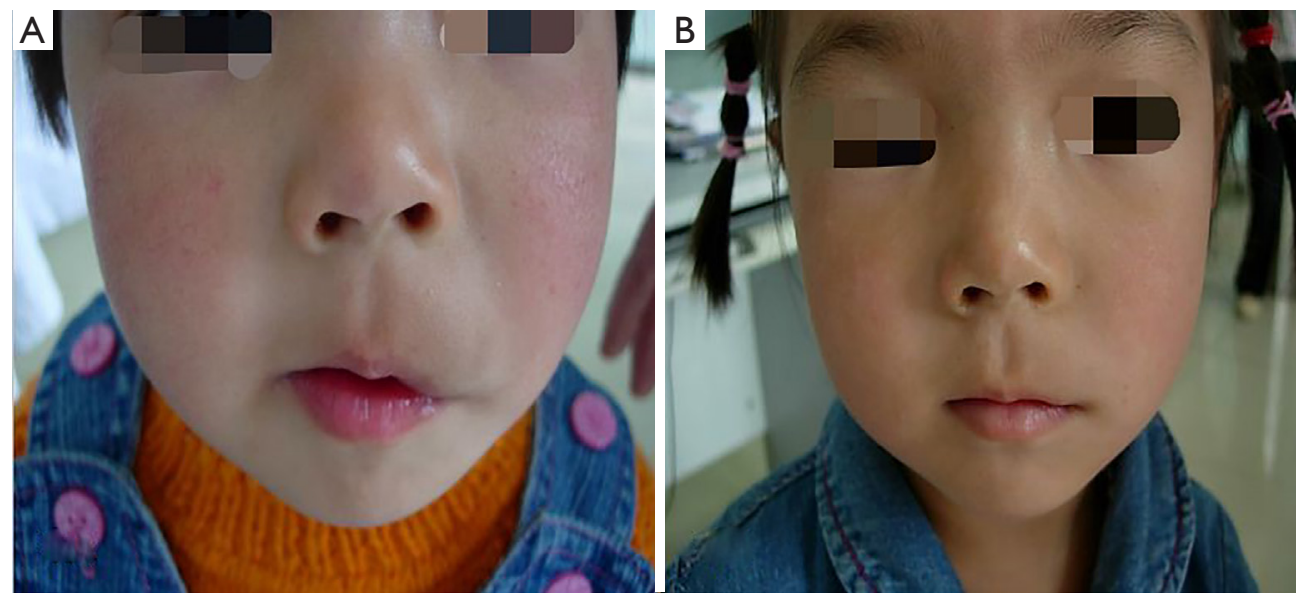

Figure 1 Female, 8 years old, with venous malformations in the skin and subcutaneous tissues of the left upper lip, which were cured after two local injections of $8 \mathrm{mg} / 3 \mathrm{~mL}$ pingyangmycin. (A) Before treatment; (B) 2 months after treatment (2 injections).
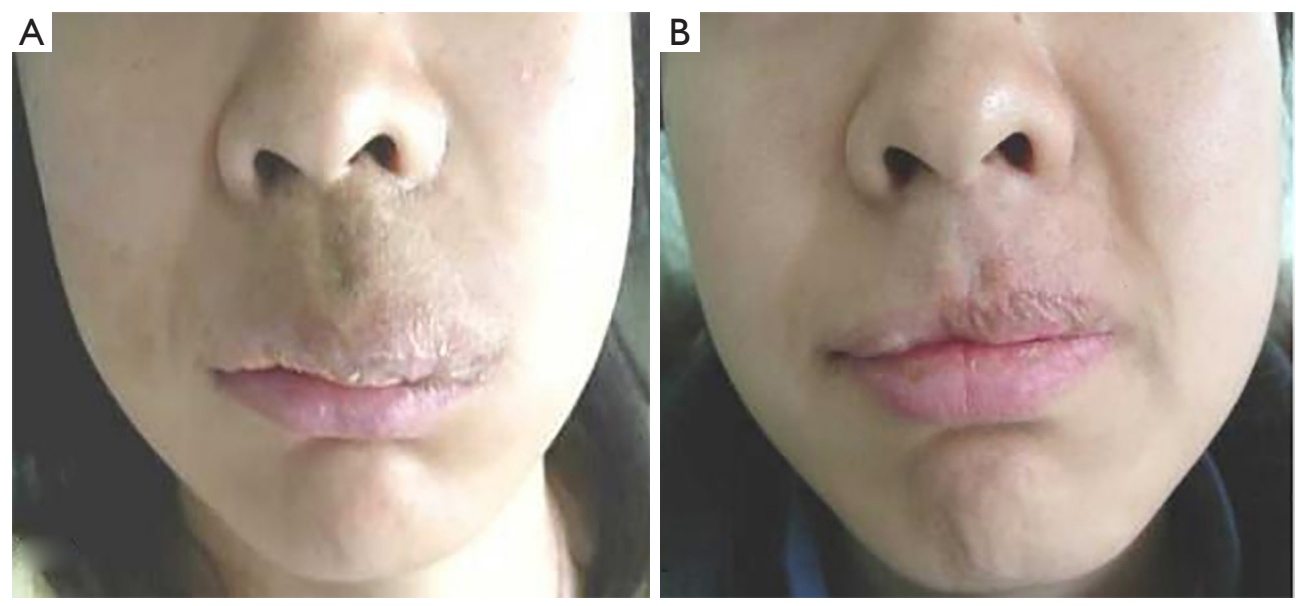

Figure 2 Female, 32 years old, with a large volume of venous malformations in the skin and subcutaneous tissues of the left upper lip, which were cured after three local injections of $8 \mathrm{mg} / 3 \mathrm{~mL}$ pingyangmycin. The patient's upper lip was significantly atrophic and thin. (A) Before treatment; (B) 2 months after treatment (3 injections).

lip of rabbits in the $8 \mathrm{mg} / 5 \mathrm{~mL}$ experimental group, $8 \mathrm{mg} / 3 \mathrm{~mL}$ experimental group, and control group was statistically analyzed, and there was no statistical difference in the three groups before the first injection $(\mathrm{P}>0.05)$. The changes of lip thickness in the experimental groups and control group after injection of different concentrations of 

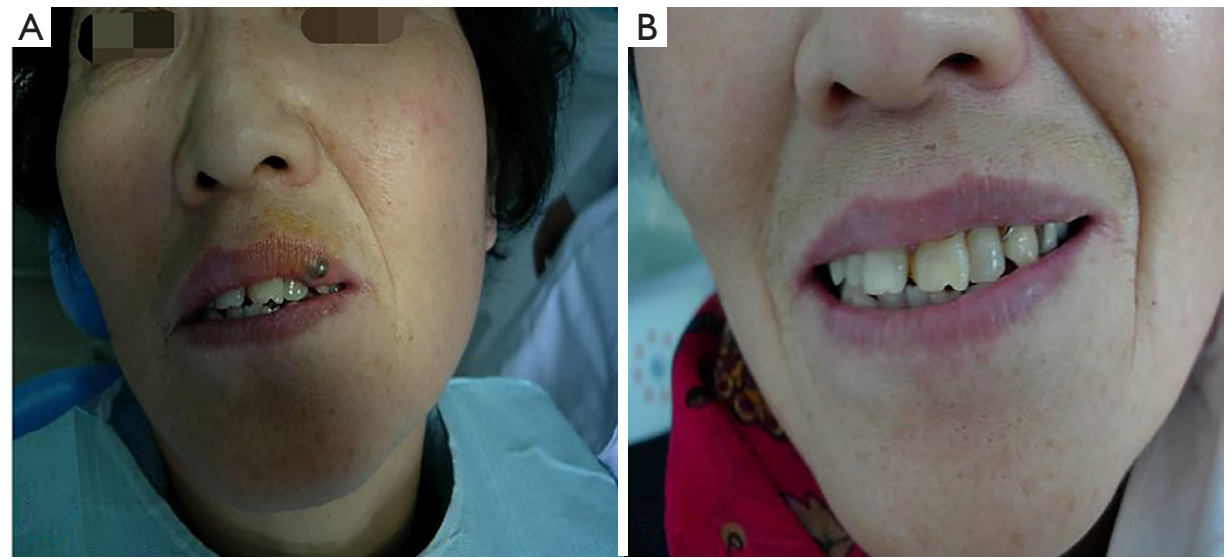

Figure 3 Female, 56 years old, with venous malformation of the red labial mucosa on the left upper lip, which was cured after a local injection of $8 \mathrm{mg} / 5 \mathrm{~mL}$ pingyangmycin. (A) Before treatment; (B) one month after treatment (1 injection).
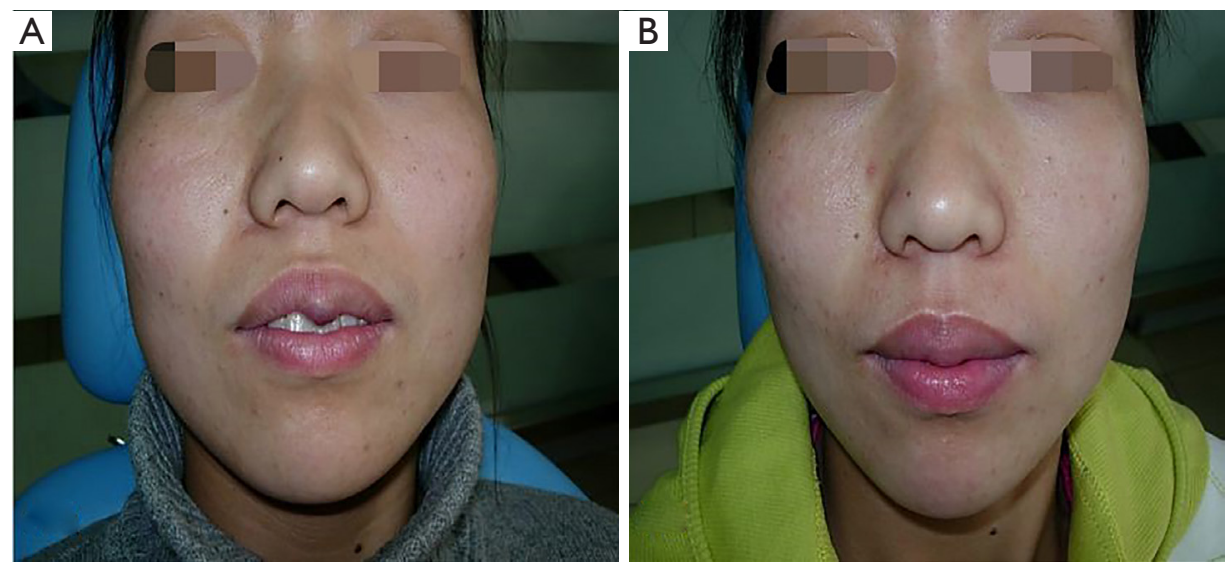

Figure 4 Female, 36 years old, with venous malformation of the upper red labial mucosa (labial tubercle) which was cured after a local injection of $8 \mathrm{mg} / 5 \mathrm{~mL}$ pingyangmycin. (A) Before treatment; (B) one month after treatment (one injection).
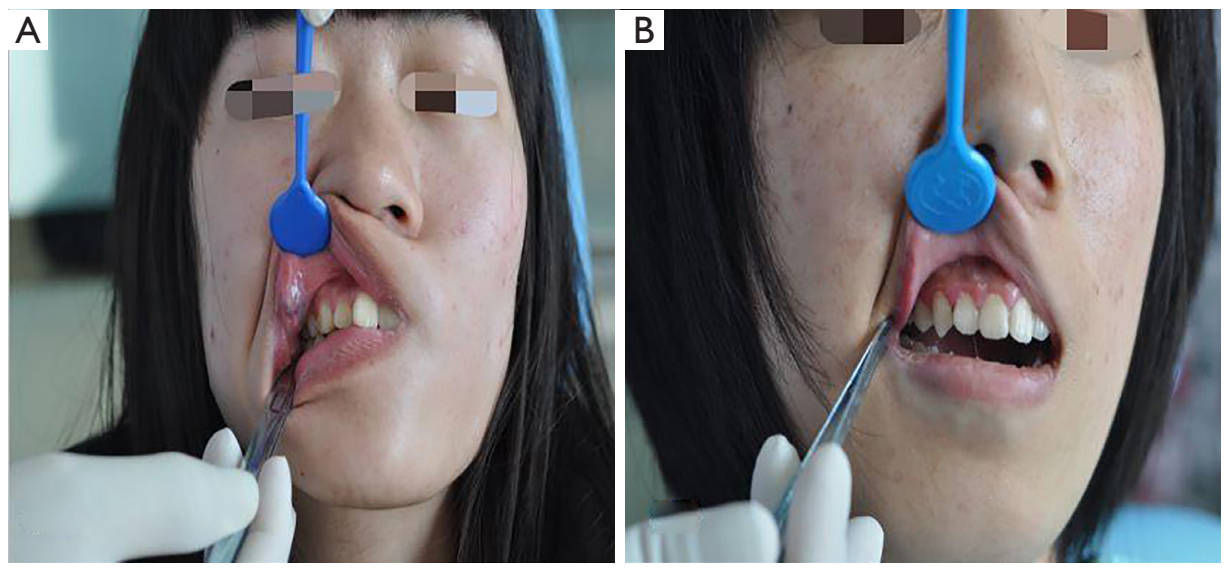

Figure 5 Female, 28 years old, with venous malformation of the right upper lip mucosa tissue who was cured after two local injections of $8 \mathrm{mg} / 5 \mathrm{~mL}$ pingyangmycin. (A) Before treatment; (B) 2 months after treatment (two injections). 
Table 3 Changes of rabbit lip thickness in experimental groups and control group after injection of different mass concentrations of pingyangmycin at different time points $\left(\bar{x}_{ \pm} \mathrm{S}, \mathrm{mm}\right)$

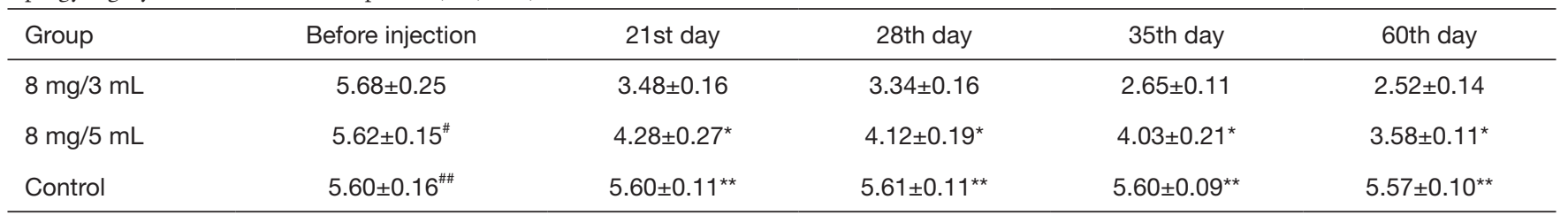

${ }^{\# \#} \mathrm{P}>0.05$ vs. $8 \mathrm{mg} / 3 \mathrm{~mL}$ group and $8 \mathrm{mg} / 5 \mathrm{~mL}$ group before injection; ${ }^{\#} \mathrm{P}>0.05 \mathrm{vs} .8 \mathrm{mg} / 3 \mathrm{~mL}$ group before injection; ${ }^{* \star} \mathrm{P}<0.01 \mathrm{vs}$. $8 \mathrm{mg} / 3 \mathrm{~mL}$ group and $8 \mathrm{mg} / 5 \mathrm{~mL}$ group at the same time point; ${ }^{*} \mathrm{P}<0.01 \mathrm{vs}$. $8 \mathrm{mg} / 3 \mathrm{~mL}$ group at the same time point.
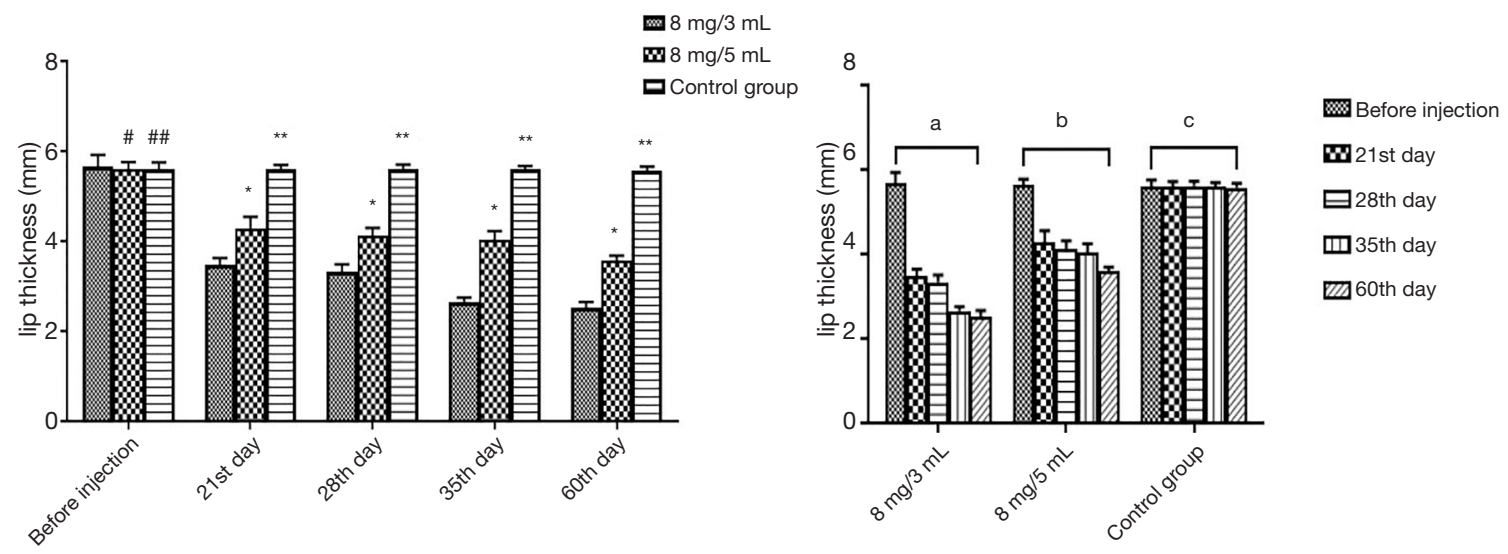

Figure 6 Comparison of rabbit lip thickness in experimental groups and the control group before and after the injection of different mass concentrations of pingyangmycin at different time points $\left(\bar{x} \pm \mathrm{s}, \mathrm{mm} ;{ }^{\# \#} \mathrm{P}>0.05 v s .8 \mathrm{mg} / 3 \mathrm{~mL}\right.$ group and $8 \mathrm{mg} / 5 \mathrm{~mL}$ group before injection; ${ }^{\#} \mathrm{P}>0.05$ vs. $8 \mathrm{mg} / 3 \mathrm{~mL}$ group before injection; ${ }^{*} \mathrm{P}<0.01$ vs. $8 \mathrm{mg} / 3 \mathrm{~mL}$ group and $8 \mathrm{mg} / 5 \mathrm{~mL}$ group at the same time point; ${ }^{*} \mathrm{P}<0.01$ vs. $8 \mathrm{mg} / 3 \mathrm{~mL}$ group at the same time point; ${ }^{\mathrm{a}} \mathrm{P}<0.01$ before injection $v s$. the $21 \mathrm{st}, 28 \mathrm{th}, 35 \mathrm{th}$, and 60 th day after injection in $8 \mathrm{mg} / 3 \mathrm{~mL}$ group; ${ }^{\mathrm{b}} \mathrm{P}<0.01$ before injection $v s$. the $21 \mathrm{st}, 28 \mathrm{th}, 35 \mathrm{th}$, and 60 th day after injection in $8 \mathrm{mg} / 5 \mathrm{~mL}$ group; ${ }^{\mathrm{c}} \mathrm{P}>0.05$ before injection $v s$. the $21 \mathrm{st}$, 28 th, 35 th, and 60th day after injection in the control group).

pingyangmycin are shown in Table 3 and Figure 6.

\section{Results of observation by light microscope in animal experiments (Figure 7)}

\section{$8 \mathrm{mg} / 5 \mathrm{~mL}$ experimental group}

On the 21 st day after injection, the vascular lumens were dilated, the vascular endothelial cells were slightly edematous, and the peripheral inflammatory cells were infiltrated (as shown by the arrow in Figure 7A). On the 28th day after injection, hyaline degeneration of collagen fibers was observed, and while no definite abnormality was found in muscles, thrombosis was found in some vascular lumens (as shown by the arrow in Figure $7 B$ ). On the 35 th day after injection, the nuclei of vascular endothelial cells were pyknosis and hyperchromatic, some capillary lumens were occluded, muscle fibers were normal and dense, and collagen fibers were relatively loose (Figure $7 C$, arrows showed thrombosis in some capillary lumens). The microscopic findings on the 60th day after injection were basically the same as those on the 35 th day after injection.

\section{$8 \mathrm{mg} / 3 \mathrm{~mL}$ experimental group}

On the 21st day after injection, inflammatory cells infiltrated around vascular endothelial cells and inflammatory cells were seen in some blood vessels (as shown by the arrow in Figure $7 E$ ). On the 28th day after injection, the vascular endothelial cells showed obvious vacuolar degeneration and some nuclei were pyknosis and deep staining. Massive thrombosis and vascular lumen occlusion were observed in the blood vessels (as shown by the arrow in Figure $7 F$ ). On the 35 th day after injection, some muscle fibers were dissolved, broken and disordered, some of the muscle tissues were replaced by fibrous connective tissue, and hyaline 

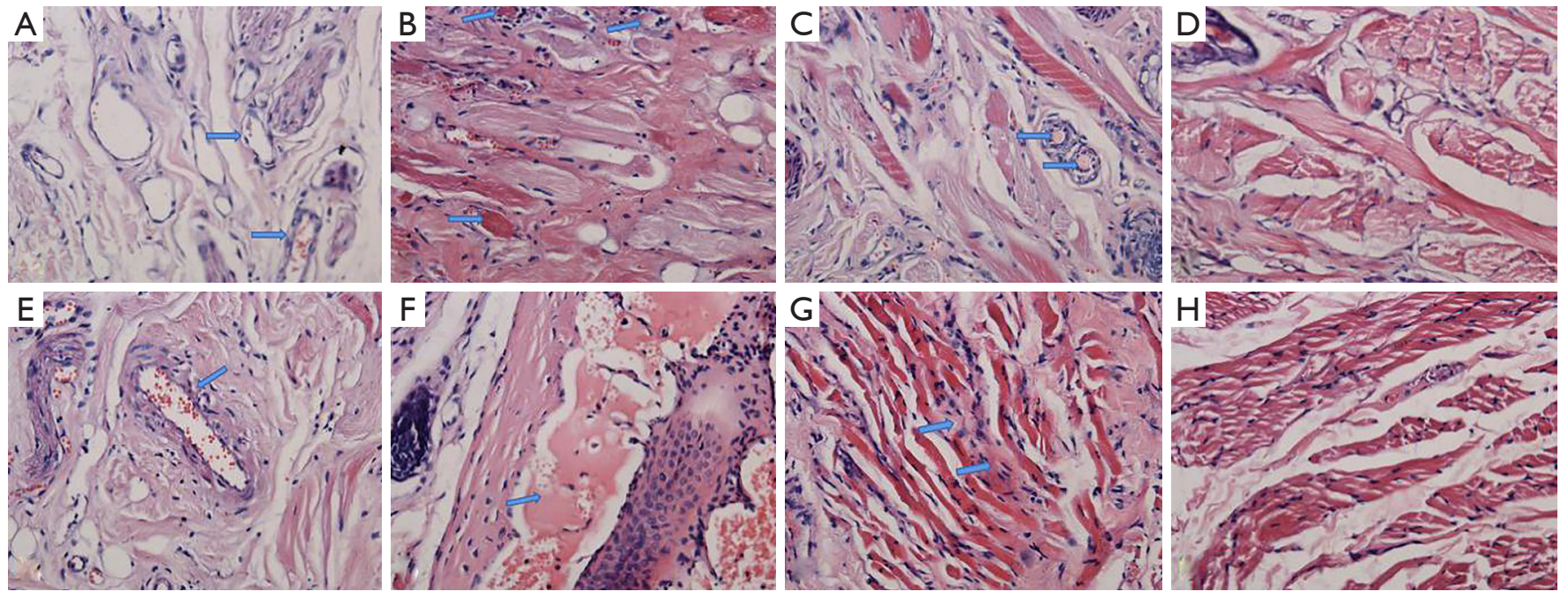

Figure 7 Histopathological changes in the lips of rabbits on the 21st, 28th, and 35 th days after injection of different mass concentrations of pingyangmycin in the experimental groups and after injection of normal saline in the control group by light microscope. (A, B, and $\mathrm{C}$ were respectively observed under light microscope on the 21st, 28th, and 35th days after injection of $8 \mathrm{mg} / 5 \mathrm{~mL}$ pingyangmycin; E, F and $\mathrm{G}$ were respectively observed under light microscope on the $21 \mathrm{st}$, 28th, and 35 th days after the injection of $8 \mathrm{mg} / 3 \mathrm{~mL}$ pingyangmycin; D and $\mathrm{H}$ were the manifestations under the light microscope on the 35 th day after injection of normal saline in the control group; HE staining, magnification $\times 400$ ). The arrows in (A) showed that the vascular endothelial cells were slightly edematous and the peripheral inflammatory cells were infiltrated. The arrows in (B) showed that hyaline degeneration of collagen fibers was observed and the thrombosis was found in some vascular lumens. The arrows in (C) showed that some capillary lumens were occluded by the thrombosis. The arrow in (E) showed that inflammatory cells infiltrated around vascular endothelial cells. The arrow in (F) showed that massive thrombosis and vascular lumens occlusion were observed in the blood vessels. The arrows in $(\mathrm{G})$ showed that some muscle fibers were dissolved, broken and disordered. There was hyaline degeneration in the collagen fibers.

degeneration in the collagen fibers was seen (as shown by the arrow in Figure 7G). The microscopic findings on the 60th day after injection were basically the same as those on the 35 th day after injection.

\section{Control group}

On the 35th day after injection, muscle fibers were normal and dense and collagen fibers were relatively loose. No definite abnormal changes were found in blood vessels (as shown in Figure $7 D, H$ ).

\section{Results of observation by transmission electron microscope in animal experiments (Figure 8)}

\section{$8 \mathrm{mg} / 5 \mathrm{~mL}$ experimental group}

On the 21st day after injection, the basal cell nucleus was round and there were many tonofilaments, microfilaments, and pinocytic vesicles in the cytoplasm. Cell junctions were observed between adjacent cells, a clear Z-line was seen in muscle fibers, and the light and dark bands were clearly defined. There were many mitochondria in muscle cells and the muscle fibers were arranged in order (as shown in Figure $8 A, B)$. On the 28th day after injection, the muscle fibers were continuous, the intermuscular mitochondria were clear, and the cristae of the mitochondria was complete. The arrangement of muscle fibers was relatively regular, and the sarcomere, Z-line, and light and dark bands were clear and close to normal (as shown in Figure 8C). On the 35 th day after injection, the arrangement of muscle fibers was relatively neat, the Z-line, sarcomere, and light and dark bands were clear, and the shape of mitochondria between muscle fibers was regular (as shown in Figure $8 D$ ). The microscopic findings on the 60th day after injection were basically the same as those on the 35 th day after injection.

\section{$8 \mathrm{mg} / 3 \mathrm{~mL}$ experimental group}

On the 21st day after injection, the arrangement of muscle fibers was irregular, and some muscle fibers were dissolved and broken. Outer membrane destruction and cristae dissolution could be seen in the mitochondria between 

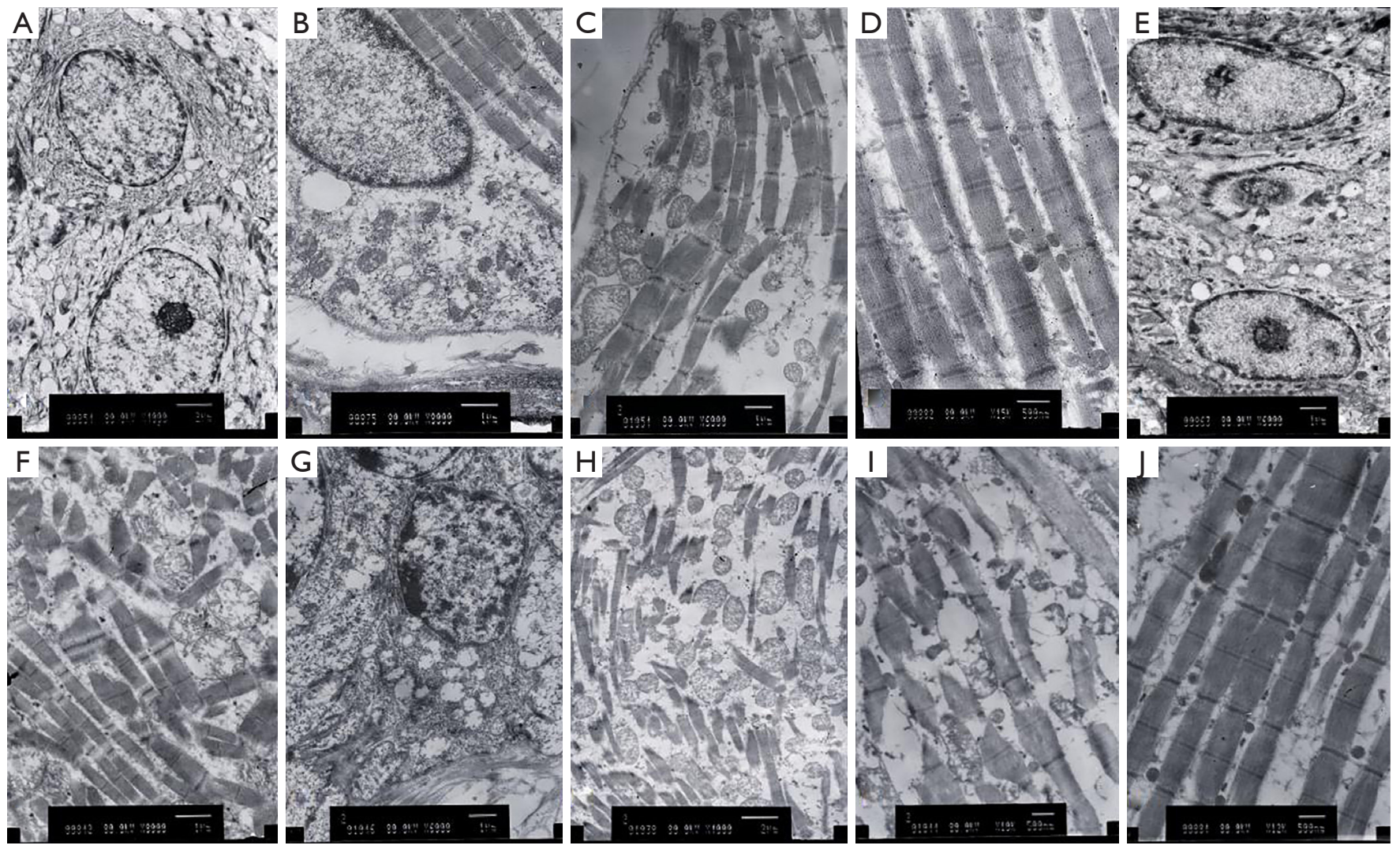

Figure 8 Histopathological changes in the lips of rabbits on the 21st, 28th, and 35 th days after injection of different mass concentrations of pingyangmycin in the experimental groups and after injection of normal saline in the control group by transmission electron microscope (TEM). (A and B, C, D were respectively observed under transmission electron microscope on the 21st, 28th, and 35th days after injection of $8 \mathrm{mg} / 5 \mathrm{~mL}$ pingyangmycin; F, G and $\mathrm{H}$, and I were respectively observed under transmission electron microscope on the $21 \mathrm{st}$, 28th, and 35 th days after the injection of $8 \mathrm{mg} / 3 \mathrm{~mL}$ pingyangmycin; $\mathrm{E}$ and $\mathrm{J}$ were the manifestations under the transmission electron microscope on the 35 th day after injection of normal saline in the control group; $80 \mathrm{kV}$, magnification $\times 1,000)$.

muscle fibers, the Z-line of muscle fibers was blurred, and the sarcomere had shortened. The boundary of light and dark bands was not clear (as shown in Figure $8 F$ ). On the 28th day after injection, the cytoplasm of basal cells was partially dissolved, and vacuolar degeneration mitochondria were found in the cytoplasm. The adjacent cell spaces were widened, the desmosomes were reduced, and the arrangement of muscle fibers was disordered and irregular. The local rupture of muscle fibers, multiple cristae defects of mitochondria, and local destruction of the outer membrane could be observed, and there was edema of myofilaments and unclear Z-lines in the microscopic findings (as shown in Figure 8G,H). On the 35 th day after injection, some muscle fibers were dissolved, the myofilaments were swollen, and the arrangement of muscle fibers was disordered. The cristae of mitochondria among the muscle fibers was dissolved, and the outer membrane of mitochondria was damaged. Some mitochondria showed vacuolar degeneration (as shown in Figure 8I). The microscopic findings on the 60th day after injection were basically the same as those on the 35 th day after injection.

\section{Control group}

On the 35th day after injection, the basal cells were clear and cell connections were observed between the adjacent cells. The nucleus was round, the chromatin was evenly distributed in the nucleus, and the nucleolus was clear. The microfilaments, tonofilaments and pinocytic vesicles were evenly distributed in the cytoplasm, and the morphology of mitochondria was normal and regular with clear cristae. The arrangement of muscle fibers was regular, and the boundaries of sarcomeres, Z-lines, and light and dark bands 
were clear (as shown in Figure 8E,7).

\section{Discussion}

The treatment of vascular disease has gradually changed from the traditional surgical treatment mode to the aesthetics mode (15). To adapt to this mode change, sclerotherapy has replaced surgical treatment and become the first-line treatment of venous malformations $(11,12,16)$. Sclerotherapy can be used as a single treatment method, or combined with flap surgery, laser, and other methods $(17,18)$. At present, there are many kinds of sclerosing agents used in the treatment of oral and maxillofacial vascular diseases. There are absolute ethanol, sapylin, sodium morrhuate, sodium tetradecyl sulfate and polidocanol. However, all the above sclerosing agents have different degrees of complications in the clinical process, which limits their application in the treatment of venous malformations. In China, the most used method for venous malformations is the well-known antineoplastic agent pingyangmycin, applied as local injection therapy (19). Pingyangmycin has a chemical structure similar to bleomycin A5, and because of its safety, convenience, rapid and effective characteristics, intralesion injection of pingyangmycin has been widely used in the treatment of oral and maxillofacial-head and neck venous malformations (20). Studies have shown that the main mechanisms of pingyangmycin in the treatment of venous malformations sees pingyangmycin bind with vascular endothelial cell DNA causing DNA strand breakage and inhibition of the metabolism of vascular endothelial cells. This could result in endothelial cell atrophy and degeneration and specific damage to vascular endothelial cells and the vascular wall. It could also induce the proliferation of vascular smooth muscle cells and endothelial cells and thicken the vascular wall, narrowing and eventually blocking its lumen. Some studies have also found that pingyangmycin can destroy vascular endothelial cells and promote the expression of adhesion molecules on the surface of endothelial cells, or release a variety of growth factors. Pingyangmycin can also promote inflammatory cell adhesion, infiltration, and inflammatory chemotaxis, and lead to the release of a variety of inflammatory factors and tissue fibrosis factors. This can promote tissue fibrosis and eventually lead to vascular lumen occlusion $(21,22)$.

Zhou et al. has shown that the effective therapeutic concentration of pingyangmycin plays an important role in the treatment for venous malformations (23). For venous malformations in different parts of the lips, we used different mass concentrations of pingyangmycin for local injection treatment and achieved good results. In our study, the overall effective rate (cured + basically cured + improvement) was $95.92 \%$ and the effective rate (cured + basically cured + improvement) of venous malformations involving the lip skin and subcutaneous tissue (pingyangmycin injection concentration $8 \mathrm{mg} / 3 \mathrm{~mL}$ ) was $93.62 \%$. The effective rate (cured + basically cured + improvement) of venous malformations involving the red mucosa and submucosal tissues of the lips using a pingyangmycin injection concentration of $8 \mathrm{mg} / 5 \mathrm{~mL}$ was $98.04 \%$. Venous malformations of the red lip mucosa with lesser volume could be cured by one injection, although three to five injections were often needed for a large range of those involving the skin and subcutaneous tissue of the lip. This may be because the fibrous connective tissue of the lip skin and subcutaneous tissue is relatively more dense, and venous malformation involving the skin and subcutaneous tissue are relatively more solid under the wrapping of dense fibrous connective tissue. However, fibrous connective tissue in the lip mucosa is relatively loose, leading to tenderness and softness of the lip mucosa. The texture of venous malformation involving the lip mucosa and submucosal tissue is also relatively soft and loose. Therefore, we used a higher concentration of pingyangmycin solution $(8 \mathrm{mg} / 3 \mathrm{~mL})$ for venous malformations involving the skin and subcutaneous tissue of the lip, which had a stronger sclerosing effect. Venous malformations involving the red lip mucosa and submucosal tissues were treated with a relatively low concentration of pingyangmycin solution $(8 \mathrm{mg} / 5 \mathrm{~mL})$, which had a milder sclerosing effect. Through the treatment, we found that venous malformations in different parts of the lip treated with different concentrations of pingyangmycin injection achieved satisfactory therapeutic effects.

Adverse reactions to pingyangmycin injection in the treatment of venous malformations are usually mild, and include swelling and pain, fever, skin reaction (local itching), gastrointestinal reaction (loss of appetite), and local ulceration and necrosis, while anaphylactic shock, pulmonary fibrosis, and leucopenia are rare $(8,19)$. In our clinical retrospective study, most of the cases showed local swelling and pain of varying degrees after pingyangmycin injection. We believe that the reason of local swelling and pain is the drug reaction caused by the sclerosing effect of pingyangmycin on vascular endothelial cells of venous malformation in the lip. Most patients complained of relatively mild swelling and pain reaction during the follow- 
up. The duration of local swelling and pain is relatively short. Most patients can tolerate the local swelling and pain response, and do not seriously affect the normal life of the patients. In our study, there was no anaphylactic shock, pulmonary fibrosis, or leucopenia although it should be noted that atrophy of lip tissue occurred when the pingyangmycin injection concentration was $8 \mathrm{mg} / 3 \mathrm{~mL}$. There have also been reports of adverse reactions resulting in the secondary malformation of lip tissue atrophy. Zhang et al. (24) reported one case of human lip venous malformation which affected the development of upper lip. During the treatment, pingyangmycin was injected into the lesion $5 \mathrm{mg}$ each time and once a week with a cumulative dosage of $40 \mathrm{mg}$, resulting in cure. However, the upper lip was too short and thin, which gradually worsened with age and affected the aesthetic effect of the upper lip. $\mathrm{Hu}$ et al. (25) reported 16 cases of secondary deformities in upper lip hemangioma and vascular malformation after local injection of pingyangmycin including six cases of venous malformation. Patients were injected on average five times with an average dosage of $20 \mathrm{mg}$ resulting in atrophy of the upper lips which saw thinning, tightening and shortening of the mucosa, skin and muscle and tightening and shortening of the upper lip. A whistling deformity of the upper lips was also present. The authors believed that the possible causes were as follows: (I) the anatomical structure of the upper lip is relatively fine and precise, and slight atrophic deformity would be obvious; (II) at the same time of curing the venous malformation, the deep labial muscle was invaded by injected drugs and the local labial muscle and soft tissue had different degrees of fibrosis, which was affecting the development of the lip and led to secondary atrophic deformity. Qiu et al. (26) retrospectively analyzed 18 children (14 girls and 4 boys) with infantile hemangioma who received local bleomycin A5 (pingyangmycin) injection treatment and found that in the 13 atrophic deformities in the upper lip, three in the nose, and two in the cheek, all were located at the injection site. The authors contend that local tissue atrophy was related to the high concentration or excessive dose of bleomycin A5 (pingyangmycin) injection which led to the arrested development of the injected subcutaneous tissue as the children aged. And this could lead to more obvious local deformities.

In our study, two kinds of pingyangmycin injection with different mass concentrations that were commonly applied in the clinical treatment of venous malformations were used in the animal experiments. A high concentration of pingyangmycin solution $(8 \mathrm{mg} / 3 \mathrm{~mL})$ and low concentration $(8 \mathrm{mg} / 5 \mathrm{~mL})$ were injected again at the same site two weeks after the first injection to simulate the clinical treatment process. In this experiment, a light microscope and transmission electron microscope were used to explore the histopathological changes and causes of adverse reactions such as lip tissue atrophy. The results showed that while a low concentration of pingyangmycin $(8 \mathrm{mg} / 5 \mathrm{~mL})$ did not cause serious damage to the blood vessels and muscles, a high concentration $(8 \mathrm{mg} / 3 \mathrm{~mL})$ caused obvious histopathological changes such as vascular injury, intravascular thrombosis, muscle tissue damage (dissolution and rupture of muscle fibers), and connective tissue fibrosis. We believe higher concentration of pingyangmycin caused destruction of the mitochondria in the muscle fiber of the lip and the fibrosis of the muscle tissue, resulting in atrophy. At the same time, the damage to the vascular endothelial cells in muscle could lead to their degeneration, the formation of massive thrombus in the vascular lumens, and vascular occlusion, which would affect the flow of blood to the muscle tissue. The results showed that the mitochondria between the muscle fibers were damaged by anoxia and vacuole degeneration, which resulted in the breaking and dissolution of the muscle fibers.

In conclusion, according to the clinical case analysis and animal experiment results in combination with the related references, we suggest that the use of high concentrations of $8 \mathrm{mg} / 3 \mathrm{~mL}$ pingyangmycin in the treatment of large-scale lip skin and subcutaneous venous malformations should be approached with caution, and with strict attention to the dose and depth of injection. Each injection dose should not exceed $8 \mathrm{mg}$, the number of injections should not exceed three to five, and the injection dose and injection time should be gradually reduced when the lesion begins to atrophy. A high concentration of pingyangmycin should also not be injected at one time, and the injection depth should be as much as possible within the lesion cavity. Injection should not be made into lip muscle tissue, to prevent complications including lip muscle atrophy, excessive fibrosis, and arrested development, which could result in an adverse aesthetic effect. The local injection of pingyangmycin $(8 \mathrm{mg} / 5 \mathrm{~mL})$ to treat venous malformations involving the mucosal and submucosal tissue of the lips was a safer, milder, and more effective concentration. However, close attention should again be paid to the dose and depth of local injection to avoid adverse reactions such as local mucosal ulceration and excessive fibrosis which may be caused by excessive injection dose and shallow injection depth.

Treatment of oral and maxillofacial venous malformations 
is challenging, and effective combination of various treatment techniques is required to achieve desired results. Intravascular sclerosis therapy is a common treatment choice at present, which has the advantages of less trauma and faster recovery. Electrochemical therapy combined with pingyangmycin injection has achieved satisfactory effect for the treatment of oral and maxillofacial venous malformations. Our team used electrochemical therapy combined with mattress cerclage and local injection of pingyangmycin to treat lip arteriovenous malformations, and achieved good clinical efficacy, providing a new method for clinical treatment of venous malformations (27). Therefore, it is necessary to select appropriate and effective combination of treatment methods according to different characteristics of lesions to achieve good improvement in appearance and function.

\section{Acknowledgments}

Funding: None.

\section{Footnote}

Reporting Checklist: The authors have completed the STROBE reporting checklist. Available at http://dx.doi. org/10.21037/atm-21-2018

Data Sharing Statement: Available at http://dx.doi. org/10.21037/atm-21-2018

Conflicts of Interest: All authors have completed the ICMJE uniform disclosure form (available at http://dx.doi. org/10.21037/atm-21-2018). The authors have no conflicts of interest to declare.

Ethical Statement: The authors are accountable for all aspects of the work in ensuring that questions related to the accuracy or integrity of any part of the work are appropriately investigated and resolved. The research plan was reviewed and approved by the medical ethics committee of the Stomatological Hospital of China Medical University and the Fourth Affiliated Hospital of China Medical University. The medication plan was approved by patients and their families, and informed consent was signed prior to treatment. All procedures performed in this study involving human participants were in accordance with the Declaration of Helsinki (as revised in 2013).

Open Access Statement: This is an Open Access article distributed in accordance with the Creative Commons Attribution-NonCommercial-NoDerivs 4.0 International License (CC BY-NC-ND 4.0), which permits the noncommercial replication and distribution of the article with the strict proviso that no changes or edits are made and the original work is properly cited (including links to both the formal publication through the relevant DOI and the license). See: https://creativecommons.org/licenses/by-nc-nd/4.0/.

\section{References}

1. Redondo P. Vascular malformations (I). Concept, classification, pathogenesis and clinical features. Actas Dermosifiliogr 2007;98:141-58.

2. Buckmiller LM, Richter GT, Suen JY. Diagnosis and management of hemangiomas and vascular malformations of the head and neck. Oral Dis 2010;16:405-18.

3. Dubois J, Garel L. Imaging and therapeutic approach of hemangiomas and vascular malformations in the pediatric age group. Pediatr Radiol 1999;29:879-93.

4. Waner M, Suen JY. Hemangiomas and Vascular Malformations of the Head and Neck. Hemangiomas and Vascular Malformations of the Head and Neck 1999:20-6.

5. Hage AN, Chick JFB, Srinivasa RN, et al. Treatment of Venous Malformations: The Data, Where We Are, and How It Is Done. Tech Vasc Interv Radiol 2018;21:45-54.

6. Carqueja IM, Sousa J, Mansilha A. Vascular malformations: classification, diagnosis and treatment. Int Angiol 2018;37:127-42.

7. Mailloux A, Grenet K, Bruneel A, et al. Anticancer drugs induce necrosis of human endothelial cells involving both oncosis and apoptosis. Eur J Cell Biol 2001;80:442-9.

8. Zheng JW, Yang XJ, Wang YA, et al. Intralesional injection of Pingyangmycin for vascular malformations in oral and maxillofacial regions: an evaluation of 297 consecutive patients. Oral Oncol 2009;45:872-6.

9. Yue H, Qian J, Elner VM, et al. Treatment of orbital vascular malformations with intralesional injection of pingyangmycin. Br J Ophthalmol 2013;97:739-45.

10. Bai N, Chen YZ, Fu YJ, et al. A clinical study of pingyangmycin sclerotherapy for venous malformation: an evaluation of 281 consecutive patients. J Clin Pharm Ther 2014;39:521-6.

11. Lee HJ, Kim TW, Kim JM, et al. Percutaneous sclerotherapy using bleomycin for the treatment of vascular malformations. Int J Dermatol 2017;56:1186-91.

12. Finitsis S, Faiz K, Linton J, et al. Bleomycin for Head and Neck Venolymphatic Malformations: A Systematic Review. 
Can J Neurol Sci 2021;48:365-71.

13. Wang XK, Bai XF, Wang S. Efficacy evaluation of pingyangmycin with different concentrations in the treatment of hemangioma and vascular malformation. Chinese Journal of Modern Surgery 2005;2:2032-3.

14. Zheng JW, Chen CJ, Zhang ZY. Intralesional lnjecfion of Pingyangmycin for Hemangiomas and Vascular Malformations in Oral and Maxilfofacial Region: A Systemafic Review of the Chinese Literature. China Journal of Oral and Maxillofacial Surgery 2003;1:102-5.

15. Wang XK. The treatment of vascular diseases. Chinese Journal of Practical Stomatology 2009;2:280-2.

16. Judith N, Ulrike E, Siegmar R, et al. Current concepts in diagnosis and treatment of venous malformations. J Craniomaxillofac Surg 2014;42:1300-4.

17. Gregory S, Burrows PE, Ellinas H, et al. Combined Nd:YAG laser and bleomycin sclerotherapy under the same anesthesia for cervicofacial venous malformations: A safe and effective treatment option. Int J Pediatr Otorhinolaryngol 2018;108:30-4.

18. Manna S, Meyer A, Shigematsu T, et al. Management of a Laryngeal Venous Malformation With Nd:YAG Laser and Bleomycin Sclerotherapy. Laryngoscope 2020;130:2199-201.

19. Division of Vascular Anomalies, Chinese Society of Oral and Maxillofacial Surgery, Chinese Stomatological Association. Guideline of using pingyangmycin to treat hemangioma and vascular malformations. China Journal of Oral and Maxillofacial Surgery 2011;9:68-9.

20. De Maria L, De Sanctis P, Balakrishnan K, et al. Sclerotherapy for Venous Malformations of Head and Neck: Systematic Review and Meta-Analysis.

Cite this article as: Yuan W, Wang X, Xue L, Zhang F. Clinical evaluation and animal experimental study of different mass concentrations of pingyangmycin in the local injection treatment of lip venous malformation. Ann Transl Med 2021;9(11):929. doi: 10.21037/atm-21-2018
Neurointervention 2020;15:4-17.

21. Tai KW, Chang YC, Chou LS, et al. Cytotoxic effect of pingyangmycin on cultured KB cells. Oral Oncol 1998;34:219-23.

22. Jia Y, Jia J, Zhao Y. Pingyangmycin-regulated expressions of adhesion molecules in human venous malformation endothelial cells. J Huazhong Univ Sci Technolog Med Sci 2012;32:760-6.

23. Zhou Q, Zheng JW, Yang XJ, et al. Concentration is more important than dose when using intralesional Pingyangmycin injection for treatment of vascular malformations. Shanghai Kou Qiang Yi Xue 2010;19:220-1.

24. Zhang YK, Ge QJ, Wang XQ. Pingyangmycin treatment of the lip venous malformation affected the development of the upper lip in 1 case. Chinese Journal of Misdiagnostics 2004;4:1355.

25. Hu XQ, Qin ZP, Li WL, et al. Clinical analysis of 16 cases of secondary deformity after local treatment of vascular anomalies of the upper lip. Chinese Journal of Medical Aesthetics and Cosmetology 2004;10:162-3.

26. Qiu Y, Lin X, Ma G, et al. Eighteen cases of soft tissue atrophy after intralesional bleomycin a5 injections for the treatment of infantile hemangiomas: a long-term followup. Pediatr Dermatol 2015;32:188-91.

27. Cheng C, Xi SL, Xu DP, et al. Mattress cerclage combined with electrochemical therapy and pingyangmycin injection after embolization for management of arteriovenous malformation on oral and maxillofacial region. J Craniofac Surg 2015;26:e110-3.

(English Language Editor: B. Draper) 